\title{
Gestión del proceso de toma de decisiones en el Colegio Técnico Profesional de General Viejo
}

\author{
Management decision-making process at General Viejo Technical High School
}

Recibido 08 octubre 2012 • Aceptado 19 junio 2013 • Corregido 30 junio 2013

\author{
Ana Gabriela Palacios Palacios ${ }^{1}$ \\ Universidad Nacional \\ San José, Costa Rica \\ anpalacios10@gmail.com \\ Keilyn Ramírez Blanco ${ }^{2}$ \\ Ministerio de Educación Pública \\ San José, Costa Rica \\ keilyn23@hotmail.com.ar \\ Adriana Rodríguez Solís ${ }^{3}$ \\ Ministerio de Educación Pública \\ San José, Costa Rica \\ solisradriana@gmail.com
}

\begin{abstract}
Resumen. La presente investigación tiene como propósito fundamental analizar la gestión del proceso de toma de decisiones en el Colegio Técnico Profesional de General Viejo, ubicado en Pérez Zeledón, provincia de San José, Costa Rica. Este estudio se caracteriza por ser descriptivo, con apoyo de técnicas cualitativas para el análisis de la información, con el fin de comprender los datos en función de la realidad educativa a la que responden. Entre los hallazgos encontrados, se manifiesta que en el proceso de gestión que se lleva a cabo no participa la comunidad educativa, ya que las decisiones son tomadas por el profesional en administración de la educación y acatadas por el cuerpo docente y administrativo, principalmente. Lo anterior, genera disconformidad entre el personal que está abierto a escuchar y participar, activamente de este proceso.
\end{abstract}

1 Máster en Gestión de Proyectos de Desarrollo del Convenio Universidad Nacional - Instituto Centroamericano de Administración Pública (UNA/ ICAP). Licenciada en Ciencias de la Educación con énfasis en Administración de la Educación del Convenio Universidad Nacional - Universidad de Costa Rica (UNA-UCR). Licenciada y Bachiller en Orientación de la Universidad Nacional (UNA), Sede Región Brunca. Se ha desempeñado como orientadora para el Ministerio de Educación Pública (MEP) y actualmente, labora para la Universidad Nacional, campus Pérez Zeledón, como Coordinadora del Programa Éxito Académico y Académica Extensionista del Proyecto Germinadora de empresas, empleos y proyectos.

2 Licenciada en Ciencias de la Educación con énfasis en Administración de la Educación del Convenio Universidad Nacional - Universidad de Costa Rica (UNA-UCR). Licenciada y Bachiller en Orientación de la Universidad Nacional (UNA), Sede Región Brunca. Se ha desempeñado como encuestadora de Proyectos de la Universidad de Costa Rica y el Instituto Mixto de Ayuda Social (UCR-IMAS). Actualmente labora como Orientadora para el Ministerio de Educación Pública (MEP).

3 Licenciada en Ciencias de la Educación con énfasis en Administración de la Educación del Convenio Universidad Nacional - Universidad de Costa Rica (UNAUCR). Licenciada y Bachiller en Orientación de la Universidad Nacional (UNA), Sede Región Brunca. Se ha desempeñado como auxiliar administrativa en educación secundaria para el Ministerio de Educación Pública (MEP). Actualmente labora como Orientadora para el Ministerio de Educación Pública (MEP). 
Palabras clave. Educación, administración de la educación, gestión de la educación, proceso de toma de decisiones.

Abstract. The purpose of this research is essential to analyze the management decision making process at General Viejo Technical High School, located in Perez Zeledon, San Jose Province, Costa Rica. This is a descriptive study with qualitative technical support for analyzing the information with the purpose of understanding the data in terms of the educational reality to which it responds. .Among the findings, it is evident that in the management process that is conducted the educational community does not participate, because decisions are taken by the professional in education administration and respected by the faculty and administration, primarily. This generates dissatisfaction among personnel that is open to listen to and participate actively in this process.

Keywords. Education, educational administration, educational management, decision making process.

\section{Introducción}

La educación, como proceso multidimensional en el que convergen conocimientos, valores y actitudes, requiere constantemente de la toma de decisiones para una efectiva y eficiente formación cognitiva, social y emotiva-afectiva de las personas, en sus diferentes etapas de vida.

Para ello, es necesaria una guía que oriente el proceso hacia las mejores alternativas de selección, considerando a la administración de la educación como el ente regulador del proceso de toma de decisiones, en la gestión que realiza en los centros educativos, en función del proceso de enseñanza - aprendizaje, ya que el objetivo de ésta es cubrir las necesidades básicas y los intereses de la población beneficiada (estudiantes, madres y padres de familia, docentes y técnicos docentes).

Las acciones conjuntas del proceso administrativo (planificación, dirección, ejecución y control) implican, en ese sentido, la constante toma de decisiones en el nivel organizacional hacia el logro de objetivos. Al respecto, Arroyo (2009) indica que la administración pretende, a través de grupos organizados de personas, el cumplimiento y logro de los objetivos y metas definidas, para los cuales se requieren procesos de tomas de decisiones importantes que marcan el curso de acción de la organización educativa.

De esta manera, la toma de decisiones tiene como fin, la elección entre diferentes alternativas para la resolución de diversas situaciones que se presentan en el marco de la gestión en los centros escolares, de forma individual o grupal.

Las decisiones que se toman de forma individual están caracterizadas, en un amplio margen, por la persona que funge la función decisoria de las mismas, puesto que utiliza su 
razonamiento y pensamiento para elegir, entre las opciones, aquella que considera mejor. Por otro lado, las decisiones que se toman de manera grupal, permiten la discusión, la reflexión y el consenso de varias personas hacia la mejor alternativa de solución, en beneficio de la comunidad educativa, en general.

De ahí, que los profesionales en administración de la educación consideren, en su gestión de procesos institucionales, la toma de decisiones participativa, estableciendo la importancia del trabajo en equipo para la consecución de los objetivos organizacionales.

Lo anterior, requiere de una persona capaz de orientar la gestión del proceso de toma de decisiones en ese sentido, ya que:

Uno de los objetivos fundamentales del liderazgo eficaz es el de ayudar al mantenimiento del interés y el esfuerzo de las personas, a través del tiempo y en relación con determinada tarea u objetivo, para el logro de la visión o el resultado deseado. Ello implica tratar cuestiones relativas a los incentivos y la motivación. (Dilts, 1998, p.130)

De ahí, que la gestión del profesional en administración de la educación en los centros educativos, implique la coordinación del personal docente y administrativo para la toma de decisiones, bajo una orientación positiva que enmarque la acción educativa en función del marco filosófico y curricular con el que opera la organización. Al respecto, Arroyo (2009) indica que la gestión directiva es la que se encarga de guiar el potencial humano y los recursos de una organización, a través de un proceso estratégico que contribuya a la organización del conocimiento, cualidades, experiencias y habilidades que de manera individual y colectiva, posee el personal docente y administrativo en un centro educativo; todo ello, para el logro de los objetivos institucionales establecidos.

En este sentido, el profesional en administración de la educación actúa como líder en los procesos de toma de decisiones, puesto que es quien coordina y organiza a su personal como equipo de trabajo para el análisis y reflexión de alternativas que los llevan a plantearse la mejor opción en una situación determinada, en beneficio de la población estudiantil y el desarrollo del proceso de enseñanza aprendizaje.

La participación de las personas colaboradoras en la toma de decisiones, es una estrategia de gestión de suma importancia en la actualidad, ya que es la manera más adecuada de orientar el curso de acción de la organización hacia los referentes planteados en su doctrina organizacional.

Para ello, la investigación se realiza bajo los siguientes objetivos para el análisis de la gestión del proceso de toma de decisiones que se lleva a cabo en el Colegio Técnico Profesional de General Viejo: 
- Describir el proceso de toma de decisiones que se lleva a cabo en el Colegio Técnico Profesional de General Viejo.

- Identificar fortalezas y debilidades del proceso de toma de decisiones que aplica la dirección.

- Identificar las estrategias que lleva a cabo la persona profesional en administración de la educación, en su gestión directiva, para la toma de decisiones.

El Colegio Técnico Profesional de General Viejo, forma parte de la Dirección Regional de Educación de Pérez Zeledón, en la provincia de San José, Costa Rica. Es un colegio que forma profesionales bajo una filosofía institucional que resalta la alta calidad humana, científica, artística, deportiva y tecnológica, con valores que le permiten al estudiantado ya egresado, un nivel competitivo en el mercado laboral.

\section{Administración de la educación}

En el sistema educativo, la administración abarca una realidad muy amplia, desde formar parte de una organización sistemática de acciones del proceso educativo, a la extensión del contexto complejo y exigente al cual responde, siendo el cambio la constante permanente y su dinámica el crecimiento organizacional. En ese sentido, la administración de la educación puede entenderse como:

la ciencia y arte que busca el logro de políticas, objetivos y propósitos educativos mediante el desarrollo de instituciones y programas que fomentan la adquisición de conocimientos, actitudes y valores humanos, sustentados en el currículo institucional, comunitario o regional, nacional y universal. (Venegas, 2001, s.p.)

De esta forma, se comprende la administración como una base que sustenta el logro de los objetivos establecidos en una institución, así como el alcance de metas claras orientadas hacia una visión y una misión presentes como una guía para la población dentro del ámbito educativo.

De ahí, que la administración de la educación se encargue, entre muchas otras cosas, de los planes institucionales y el currículo educativo que se desarrolla, en el nivel macro y micro de las organizaciones educativas, siendo una fuente de apoyo a estos y otros factores que, de alguna u otra forma, intervienen en el proceso, desarrollo y ejecución del plan académico del centro escolar.

Por ello, busca garantizar nuevas y factibles formas de alcanzar cada meta, objetivo y a proyecto establecido dentro del sistema educativo, así como organizar todas aquellas áreas 
que faciliten esta labor. Lo anterior, permite concebir una administración de la educación que "conlleva la responsabilidad de conducir adecuadamente los proceso de la gestión educativa en los distintos niveles y modalidades de la educación [...] para poder alcanzar el desarrollo de los aprendizajes con altos parámetros de calidad" (Garbanzo y Orozco, 2007, p. 97).

En ese sentido, se contempla el trabajo conjunto de la comunidad educativa para la consecución de los objetivos institucionales, a partir del desarrollo de procedimientos como planeación, organización, dirección, control y evaluación de las acciones educativas en los centros escolares (Arroyo, 2009).

Asimismo, Salas (2003) indica que la administración de la educación se encarga de administrar todo lo referente al currículum, en todos sus componentes, en las instituciones educativas, incluyendo la planificación, dirección, ejecución y control de los recursos materiales, financieros y humanos.

Así, se contempla el proceso administrativo como un ente de funciones vitales para el sistema educativo, con el fin del mejoramiento de la calidad de la educación, desde una administración efectiva en su gestión.

\section{Gestión de la educación}

La gestión es el proceso por el cual se presentan, de manera integral, coherente y unificada, las decisiones por parte del profesional en administración de la educación en los centros educativos, para la definición y logro de los objetivos institucionales planteados, planes y prioridades en lo que refiere al desarrollo curricular, recursos humanos, financieros, materiales, entre otros. De ahí, que la gestión educativa debe entenderse como:

una acción colaborativa de parte de un grupo de personas, las cuales constituyen un equipo de trabajo; lo que no implica el ejercicio ni responsabilidad de una sola persona, sino que la gran responsabilidad que tiene el centro educativo necesariamente debe ser asumido por un conjunto de personas que, comprometidas con un propósito común, conforman y consolidan un equipo de trabajo. (Castillero, Díaz, Morales y Pino, 2009, p. 13)

Así, la gestión en la administración de la educación, consiste en una serie de acciones que realiza la dirección de la institución educativa, en función del logro de objetivos y metas comunes, a partir del trabajo de la comunidad educativa como equipo de trabajo.

De ahí, que sea relevante la gestión en el centro educativo como un proceso donde se enmarca el desarrollo estratégico institucional, de manera integral y coherente, para la definición de objetivos, acciones y prioridades que comprometen a todos los actores institucionales (Ledo, 2008). 
El proceso de gestionar adecuadamente la educación, conlleva una serie de acciones que coordinadas, permiten el desarrollo de estrategias sobre bases sólidas, que fundamenten el trabajo ejercido por la dirección en las organizaciones educativas y su equipo de apoyo, ya que requiere la actuación constante y dinámica en función del proceso educativo al que responde. De ahí, que la gestión se enfoque en personas líderes de las organizaciones educativas, quienes procuren delimitar el ejercicio profesional de la comunidad educativa, en general, hacia la consecución de los objetivos establecidos, con el fin de mejorar la calidad del servicio educativo que se brinda a la población estudiantil.

\section{Proceso de toma de decisiones}

En la gestión de las organizaciones educativas se manifiesta una función específica que enmarca el accionar, individual y colectivo, hacia el logro de las metas institucionales: la toma de decisiones. Este proceso comprende la capacidad que tiene una persona u organización al momento de elegir una opción, con la visión de seleccionar siempre la mejor alternativa en relación directa con el marco de ejecución al que responde, en beneficio de la comunidad educativa, en general y por ende, del sistema educativo.

De ahí, que la figura del profesional en administración de la educación adquiere relevancia, puesto que desde su gestión directiva, define el proceder para la toma de decisiones, en función del marco doctrinal que enmarca la acción del ser y quehacer organizacional. Para ello, requiere del apoyo y participación de su equipo de trabajo, la población estudiantil, padres y madres de familia, así como de la comunidad a la que pertenece el centro educativo, con el fin de considerar la toma de decisiones como un proceso de todos y para toda la comunidad educativa.

Así, el proceso de toma de decisiones conlleva elegir la mejor opción, en un tiempo determinado, en función de la situación que se esté presentando en la institución. Para ello, Hastie (2001) plantea una serie de aportes al proceso de toma de decisiones, en relación con la definición de los principales términos que intervienen en él. A saber:

- Decisiones: combinaciones de situaciones y conductas que pueden ser descritas en desde tres componentes esenciales: acciones alternativas, consecuencias y sucesos inciertos.

- Resultado: situaciones describibles públicamente que ocurren cuando se llevan a cabo las conductas alternativas que se han generado.

- Consecuencias: reacciones evaluativas subjetivas, medidas en función de acciones asociadas con cada resultado como bueno o malo, ganancias o pérdidas, otros.

- Incertidumbre: juicios de quien toma la decisión de la propensión de cada suceso a ocurrir. Se describe con medidas que incluyen probabilidad, confianza y posibilidad.

- Preferencias: conductas expresivas o intenciones de elegir un curso de acción sobre otros. 
- Tomar una decisión: refiere al proceso entero de elegir un curso de acción.

- Juicio: componentes del proceso de decisión que se refieren a valorar, estimar, inferir los sucesos a ocurrir las reacciones evaluativas del que toma la decisión en los resultados que obtenga.

Desde esa perspectiva, una decisión de gran calidad ayuda a la organización a alcanzar sus metas estratégicas, por medio del mejor curso de acción posible en función de muchos otros posibles, a través de un análisis a conciencia con la debida participación de la comunidad educativa que involucra la misma.

En ese sentido, es probable que el proceso de toma de decisiones acertado, produzca mayor utilidad, servicio o desempeño de la organización educativa, puesto que satisface las necesidades de todas las personas que tienen un interés en ella (Gordon, 1997).

Como en toda organización, en los centros educativos la máxima autoridad está en posición de decidir lo mejor para el desempeño institucional, mediante el estudio profundo de las posibilidades de acción, considerando los recursos con los que se cuenta, las oportunidades que se tienen, el apoyo humano y, por supuesto, la tolerancia y comunicación para sondear los mecanismos que permitan elegir la mejor opción. Por esa razón, Gordon (1997) menciona que:

Los administradores y quienes toman las decisiones también deben evaluarlas de acuerdo con la medida en la que se ciñen los criterios de la ética. Las partes interesadas, los intereses y valores que suelen ser múltiples y discordantes, al igual que las leyes ambiguas, muchas veces conducen a problemas de ética. (p. 214)

Para ello, el profesional en administración de la educación puede recurrir a las categorías de decisiones establecidas por Herrera (s.f.), en función de si son o no acciones programadas.

Decisión programada: aquellas acciones repetitivas y rutinarias ya definidas por las situaciones o circunstancias que se presentan, con las cuales se ha desarrollado un método definitivo para manejarlas por estar el problema bien estructurado. Ante esta situación, el mando no tiene necesidad de pasar por el trabajo y gasto de realizar un proceso completo de decisión.

Decisión no programada: aquellas acciones que responden a situaciones imprevistas, nuevas y no conocidas en la organización, lo que requiere de procesos de reestructuración, estudio, creación de estrategias innovadoras y otros, para llegar a la mejor selección de acuerdo con la problemática planteada. 
Ambos tipos de decisiones se utilizan en diversas situaciones que se viven a diario en las instituciones educativas, lo que permite el planteamiento de estrategias de intervención para dar solución en el momento oportuno, de manera grupal e individual, a partir de referencias precisas que conllevan la mejor selección de la decisión a tomar.

De ahí, que la toma de decisiones sea un proceso complejo que requiere de una serie de pasos elaborados, ya que las consecuencias de la misma no deben de repercutir en la organización, donde se pueden ver desenvueltos conflictos por un mal actuar.

Al respecto, el proceso de toma de decisiones conlleva, al menos, la elección de alternativas desde la definición del problema, el análisis del mismo, la evaluación de las alternativas de acción, la selección de la mejor de ellas y la aplicación en el contexto. Por su parte, Chiavenato (2002) refiere que la toma de decisiones es un proceso complejo que:

- Identifica la situación

- Define la situación

- Diagnostica las causas de la situación

- Identifica los objetivos

- Transforma la solución o curso a seguir

- Evalúa la aplicación de la decisión definida

En ese sentido, la toma de decisiones se determina por medio de un proceso a seguir para la definición de las acciones a desarrollar, con el fin preciso de alcanzar una meta u objetivo, mediante un análisis de probabilidades. De ahí, que se entienda el proceso de toma de decisiones como el sistema para identificar y seleccionar un curso de acción específico, que permita enfrentar un problema determinado u obtener ventajas de una situación dada (Chiavenato, 2001).

De esta forma, se identifica que la toma de decisiones es un proceso de análisis y comprensión que, a pesar de que la decisión sea programada o no programada, requiere el seguimiento de una línea de acción tomando en cuenta las partes y situaciones involucradas en la cuestión a tratar. Por tanto, el profesional en la administración de la educación debe tener cautela y medir las implicaciones que la decisión puede tener en su centro educativo y en el contexto que se alberga dentro de la comunidad educativa.

Lo anterior, lo refiere Chiavenato (2004) al mencionar los elementos del proceso de toma de decisiones, los cuales establecen las disposiciones para el análisis referido de las circunstancias. Así, se considera el ambiente en el que surgen las decisiones (estado de la naturaleza), el grado de predicción de resultados de cada alternativa de acción (ambiente de certeza, riesgo e 
incertidumbre), la o las personas involucradas en la selección de la mejor alternativa de acción (agente decisorio), los fines establecidos a partir de los resultados que genera la decisión a tomar (objetivos), los criterios para la toma de decisiones (preferencias), el alcance mayor de metas por los cursos de acción (estrategias) y las consecuencias y resultados de las estrategias determinadas (resultados).

De esta forma, en el proceso de toma de decisiones se dan una serie de particularidades que pueden repercutir positiva o negativamente en el logro de objetivos, por lo que debe llevarse a cabo el proceso tal cual se describe, para un mayor éxito en los resultados.

\section{Estrategias de la gestión directiva para el proceso de toma de decisiones}

Las acciones de gestión que tienen lugar para la toma de decisiones en una organización educativa, tienen su proyección de ejecución en función de las estrategias para el funcionamiento y desarrollo del quehacer curricular.

En ese sentido, la gestión se centra en un conjunto de acciones dirigidas al logro de los objetivos institucionales, a partir de las experiencias, conocimientos, habilidades, individuales y colectivas, en relación con la realidad educativa a la que responden.

De esta manera, las estrategias de gestión directiva se vinculan con el proceso de toma de decisiones, desde la resolución de conflictos, el liderazgo, la comunicación y las relaciones interpersonales.

\section{Resolución de conflictos.}

El rol del director es el de calmar las ansiedades o dar un marco contenedor de cambio, que permita restablecer los equilibrios correspondientes, quizás una solución es la de ir pensando, anticipando en equipo las posibles variables de cambio que implican cada reestructuración.

Un conflicto es una situación en donde se confrontan ideas o creencias totalmente distintas, que pueden afectar la percepción de la otra persona y que exigen la búsqueda de una solución. Al respecto, Robbins (1999) señala que "el conflicto es un proceso que comienza cuando una parte percibe que otra parte la ha afectado en forma negativa, o está por aféctala en forma negativa, en algo que la primera parte estima" (p. 505).

En las instituciones educativas, se presentan muchas y muy diversas situaciones que pueden llevar a un conflicto, ya sea por diferencia de opiniones entre los docentes o por situaciones más personales, como un rechazo hacia otra persona. 
Para llegar a la resolución de un conflicto, es necesario contar con una persona mediadora que funcione como un escucha y facilitadora de ideas para encontrarle una solución al problema, debe siempre ser neutral; es decir, no tener inclinación hacia ninguna de las ideas que se están disputando.

En ese sentido, "para manejar el conflicto (y su propia seguridad) usted necesita controlar la tolerancia del grupo a las tensiones" (Heifetz y Linsky, 2003, p.111). Es evidente, que cuando en una organización existe mucha demanda laboral y no hay medios para canalizar esa tensión, las personas se sienten ofuscadas, viéndose afectados en su comportamiento. Por ello, es responsabilidad del director, buscar los medios para canalizar esas tensiones en el grupo con el que labora.

Es importante que el administrador implemente técnicas para trabajar este aspecto, que cuente en la institución con un profesional (como mínimo) encargado de trabajar la parte emocional, que funcione como un apoyo para que los demás profesionales puedan liberar su estrés, que le confíen sus dificultades, sus problemas, y así puedan alivianar sus cargas emocionales, que pueden afectar directamente su desempeño laboral.

Del mismo modo, el director debe, como autoridad, velar por el bienestar de sus subalternos; en este sentido, se puede hablar de talleres de motivación, de relajación, entre otros, con el fin de mejorar situaciones de tensión que se originen en el campo laboral.

\section{Liderazgo.}

Es completamente normal queel ser humano, en condición de autoridad, desarrolle un sentimiento de poder, de tal forma que pueda empoderarse de la responsabilidad que le ha sido asignada y no solo de una etiqueta que lo fija como director o autoridad, para así brindar excelencia en su trabajo.

Sin embargo, en las visiones más actuales de liderazgo, los líderes no tienen influencia por el mero hecho de ser jefes o comandantes. Se trata más bien de personas comprometidas con crear un mundo al que las personas deseen pertenecer. Este compromiso requiere una combinación especial de modelos y habilidades que permita manifestar efectiva y ecológicamente las visiones que guían a quienes se comprometen con el cambio. Entre estas habilidades se incluyen las de comunicación, interacción y gestión en el seno de cualquier organización, red o estructura social, con el objetivo de encaminar a cada cual hacia el logro de sus aspiraciones más elevadas. (Dilts, 1998, p. 23)

En el desempeño administrativo, y en este caso de la educación, se requiere contar con un perfil para ejercer en ese puesto. Este perfil comprende ciertas características; siendo la principal o la más importante, la capacidad de ejercer un buen liderazgo.

Así, considerando la definición propuesta por el Diccionario de la Lengua Española (1986) y el Diccionario de Ciencias de la Conducta (1956), citados por Montenegro, Camiña, Muños y 
Mazza (2007), el liderazgo se define como la dirección o conducción de una persona hacia un grupo social o colectividad, a partir de cualidades personales y capacidades que permiten guiar y controlar el accionar de los individuos hacia objetivos comunes.

Por su parte, Chiavenato (1993) destaca que el liderazgo es una influencia interpersonal que se ejerce en una situación y que dirige a través del proceso de comunicación en la consecución de diversos objetivos.

La función del líder busca el encuentro de momentos para ayudar al grupo que lidera, para cumplir con las tareas; de tal forma que alienta y motiva a los otros a que lo sigan, en el desarrollo de las capacidades del personal docente y administrativo.

Algunos autores, definen los estilos de liderazgo basándose en las siguientes características, según el proceso de toma de decisiones. Así, se determinan los estilos básicos de:

El líder autócrata, quien asume toda la responsabilidad de la toma de decisiones; inicia acciones, dirige, motiva y controla; pues considera que solo él es competente y capaz de tomar decisiones importantes.

El líder participativo, quien utiliza la consulta sin delegar su derecho a tomar decisiones finales; además, escucha y analiza ideas que le proponen.

Líder liberal, quien delega la autoridad para la toma de decisiones. Estipula cierto número mínimo de reglas para guía y control.

El administrador de la educación debe conocer los tipos de liderazgo que se mencionaron anteriormente, con el fin de autoevaluarse y saber si es el que realmente necesita la institución donde labora, si cubre las expectativas y las necesidades de dicho centro.

\section{Comunicación.}

El proceso de comunicación comprende un espacio muy amplio y en ocasiones muy complicado, ya que comunicar no solo significa decir lo que se siente o se piensa, sino que comprende aspectos más complejos como la necesidad de una vía de comunicación, un emisor, un receptor, un mensaje, y cada uno de estos a su vez, contiene una función para que todo este proceso de transmisión se llegue a convertir en una comunicación.

Al respecto, Caldeiro (2005) afirma que la palabra comunicación parte del latino "comunis" que significa "común", por lo que involucra la transmisión de ideas con el objetivo de hacerlo partícipe de otros, mediante un código compartido.

Es por ello, que en el desarrollo social y en cada área que a este comprenda se requiere de una adecuada comunicación, y para ello se necesita como se menciona anteriormente, de 
un código compartido, es decir; transmitir ideas, pensamientos o sentimientos que puedan ser interpretados o leídos por el individuo que lo recibe; o sea, que la otra persona comprenda el lenguaje que se transmite.

En el sistema educativo, una comunicación asertiva es la mejor herramienta para combatir la deserción, las diferencias y un sin fin de dificultades que surgen en el proceso y que en muchos casos dificultan el logro de los objetivos.

"La asertividad es la manifestación adecuada de nuestras opiniones y sentimientos; es decir, sin agredir a los demás pero asumiendo el respeto y dignidad propios" (Vidal, 2000, p. 31).

Una comunicación asertiva comprende, entonces, una transmisión exacta de lo que se quiere decir; así, como el respeto propio y hacia los demás, tratando de no ofender o maltratar con lo que se dice.

Del mismo modo, debe contemplar la forma en que está organizada la institución educativa, la visión y la misión que plantean, la cultura organizacional para reflexionar aspectos como los prejuicios que muchas veces se hacen las personas de los demás y que va a afectar, de forma positiva o negativa, al momento de comunicarse entre sí.

Los administradores de la educación deben considerar si cuentan con las características anteriormente mencionadas, para así, determinar si el plan de comunicación que se tiene, intenta utilizar todos los aspectos necesarios para ofrecer un mensaje claro y comprensible.

Un buen comunicador trata de analizar aspectos que le favorezcan a la hora de comunicar, como la población a la que se dirige, pues, de ello, depende mucho la comprensión de lo que se comunica, ya que, si la comunicación es asertiva el mensaje que se quiere transmitir va a ser fluido y captado más claramente por el receptor.

La capacidad de comunicación que posee el líder y la relación que pueda ejercer con los demás dentro de la organización, apoyará un liderazgo eficaz, al fomentar la confianza y la comunicación por parte de los trabajadores, facilitando el logro eficiente de los objetivos propuestos y un alcance exitoso en las tareas que debe desempeñar el grupo.

\section{Relaciones interpersonales.}

Las relaciones que puedan abrirse entre los docentes-director y viceversa, tendrá un efecto positivo o negativo en el desempeño individual y colectivo dentro de la institución, y en la eficiencia con la que se logren los objetivos y los planes propuestos, ya que fomentará el trabajo en equipo y por ende éxito en el logro de las metas educativas. 


\section{Marco Metodológico}

La investigación que se llevó a cabo, posee características de corte cualitativo, ya que "pretende la descripción detallada de situaciones, eventos, personas, interacciones, conductas observadas y sus manifestaciones" (Hernández, Fernández y Baptista, 2010, p. 9). Además, la investigación cualitativa proporciona profundidad a los datos y contextualización en el ambiente y/o situación determinada.

A su vez, se considera de tipo descriptivo ya que se dirige a determinar como está la situación en estudio, tal como lo manifiestan Hernández et al. (2010) cuando indican que los diseños descriptivos refieren la incidencia de las variables o categorías sobre el contexto en el cual se lleva a cabo la investigación.

Para ello, se recurre a la participación de sujetos clave en el centro educativo, por lo que se consideran en la investigación el personal docente-administrativo, el personal administrativo y de servicio, el personal docente y el profesional de la educación a cargo del Colegio Técnico Profesional de General Viejo.

La tabla 1 refleja la participación de los sujetos informantes, por grupo profesional. Para una mejor comprensión de los participantes, la información se detalla además por sexo, para tener referencia numérica de los hombres y mujeres en el estudio.

Tabla 1

Muestra personal docente-administrativo, administrativo y de servicio y docentes Colegio Técnico Profesional de General Viejo.

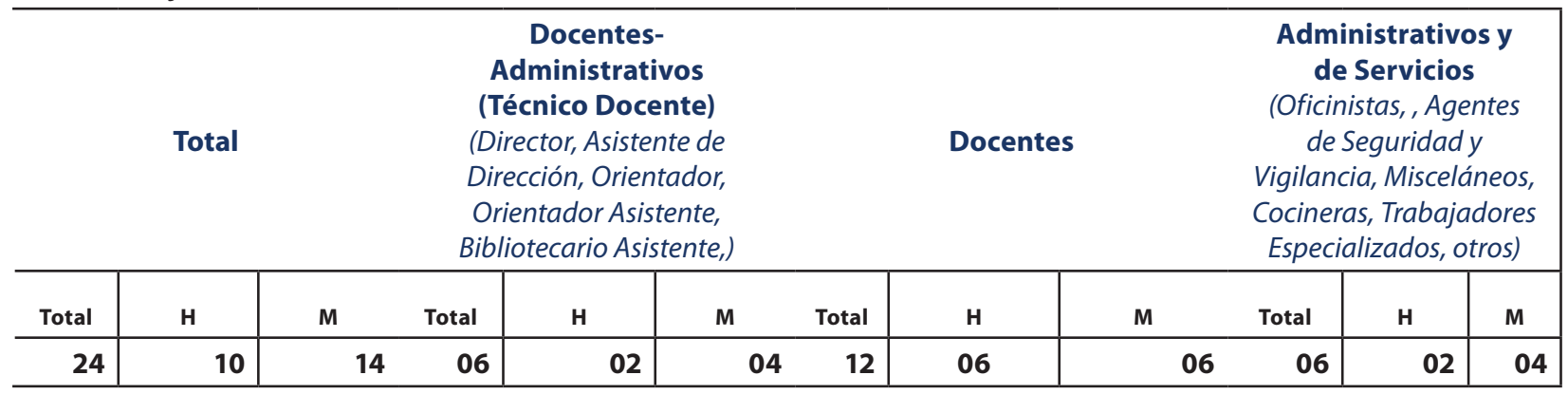

Nota: Formularios matrícula final -2006-2007-2008-2009

De acuerdo con la información suministrada, se considera un total de 24 personas participantes en la investigación, de los cuales seis son personal docente-administrativo, 12 docentes y seis personas administrativas y de servicio, elegidos por conveniencia en relación con el tema en estudio. 
Para el desarrollo de la investigación, se sustenta la estrategia metodológica en las siguientes categorías de análisis, a partir de los objetivos específicos establecidos:

- Proceso de toma de decisiones: tipos de decisiones, modelos y pasos secuenciales para la toma de decisiones

- Fortalezas y debilidades del proceso de toma de decisiones: contexto interno y externo en relación con el proceso de toma de decisiones

- Estrategias delagestión directiva para la toma dedecisiones:mecanismos decomunicación, percepción y estilos de liderazgo, instancias para la toma de decisiones, participación de la comunidad educativa

En función de las técnicas e instrumentos para la recolección de la información, esta investigación desarrolla sesiones individuales y colectivas en profundidad, con los sujetos participantes. Así, la sesión individual se realiza con el profesional en administración de la educación, a través de una entrevista semiestructurada y la aplicación de un análisis situacional tipo FODA sobre el proceso de toma de decisiones.

Las sesiones colectivas, en profundidad, se llevan a cabo con el personal docenteadministrativo, docente y administrativo y de servicio de la institución que se eligió como muestra para este proceso. De acuerdo con Hernández et al. (2010), las sesiones en profundidad son una especie de entrevistas grupales que consisten en reuniones pequeñas, en los grupos anteriormente mencionados, en los cuales se conversan sobre la temática en estudio. De esta manera, se desarrolla una guía semiestructurada de preguntas y el diagnóstico FODA, con el grupo participante.

\section{Análisis de los datos}

A partir de los datos obtenidos, se efectúa una triangulación entre lo referido por el director en la entrevista y el análisis situacional, lo que dice el resto del personal docente-administrativo, docente y mantenimiento en la entrevista y el análisis situacional y la teoría en relación con la temática, que marca las bases conceptuales en las que deben sustentarse las acciones en la gestión directiva de los procesos de toma de decisiones.

Los resultados se muestran mediante figuras y cuadros comparativos que sirven de base para el análisis de la información, enfatizando en las categorías desarrolladas en la investigación y las subcategorías más sobresalientes.

Para efectos de conocimiento de la presentación de los datos, se trabaja con la triangulación de la información que responde a la triangulación de la información suministrada por los siguientes informantes: director - personal docente y administrativo, en relación con la teoría referente a la administración de la educación y sus procesos de gestionamiento, donde cada 
elemento influye para el análisis de las categorías y subcategorías planteadas en la investigación. Para cada una de ellas, se describe, detalladamente, lo recolectado en el trabajo de campo, fundamentado en las opiniones de los informantes, las figuras y cuadros de información, en conjunto con la triangulación de las ideas brindadas por la población objeto de estudio.

Asimismo, se trabaja con un color específico para cada uno de los objetos de estudio, a saber: el director se identifica con el color morado, el personal docente y administrativo con el color azul y la teoría, con el color celeste.

\section{Proceso de toma de decisiones}

La consideración de opciones antes de determinar los pasos a seguir en las organizaciones educativas, conlleva un proceso de toma de decisiones fundamental para el mejoramiento continuo de los centros educativos. Toda la comunidad educativa debe participar en este proceso, debido a que las decisiones que se tomen van a estar directamente vinculado con todos los agentes educativos a lo interno y externo de la institución.

Uno de los principales papeles para liderar este proceso, es el de la persona encargada de la administración del centro educativo, quien dirige los procesos de gestión en las organizaciones, en colaboración con el personal docente y administrativo.

Para la presente investigación, se construye la siguiente figura, en la que se muestra la triangulación que, sobre el proceso de toma de decisiones, establece los criterios teóricos del director y del personal docente y administrativo del Colegio Técnico Profesional de General Viejo. 


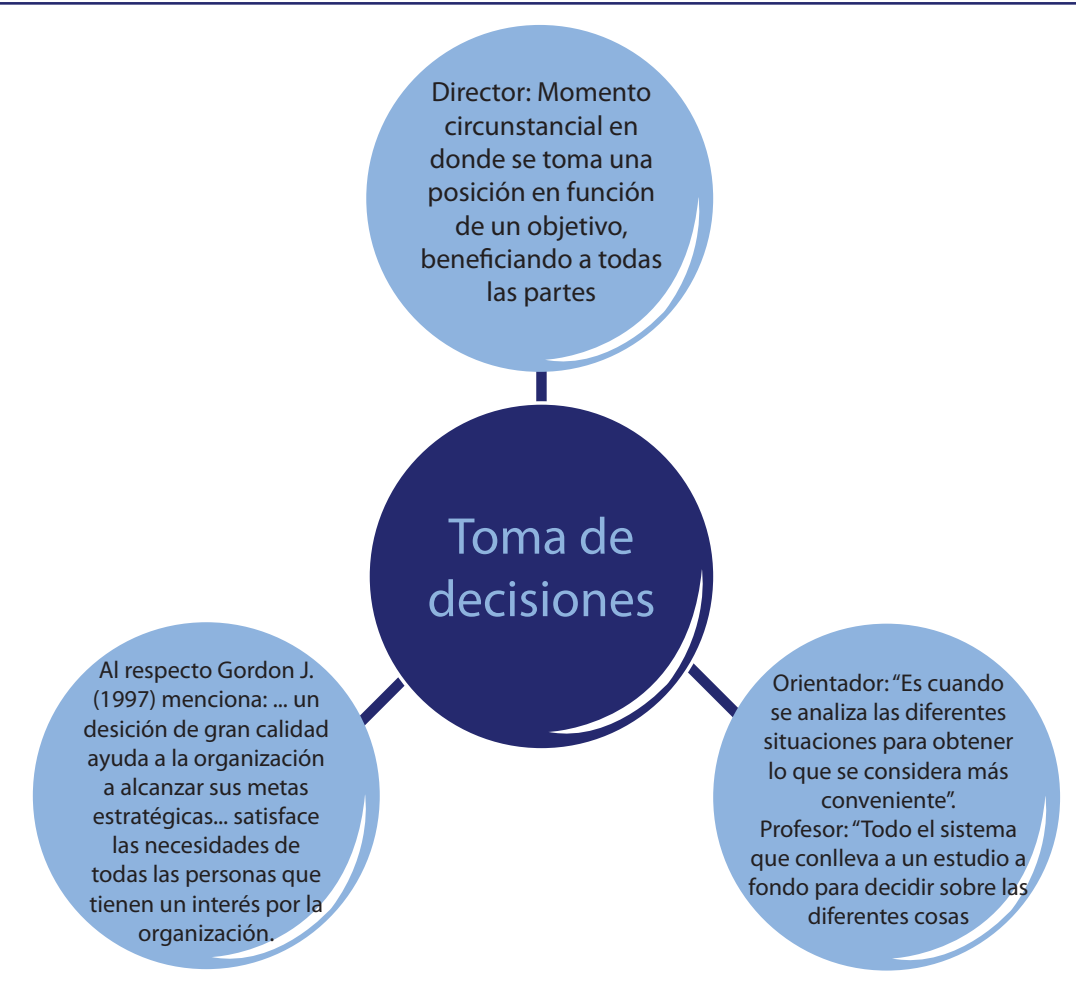

Figura 1 Proceso de toma de decisiones

Nota: Sesión individual y colectiva realizada con el director y personal docente y administrativo del Colegio Técnico Profesional de General Viejo. Compilación de los referentes conceptuales en el marco teórico de esta investigación.

Como se demuestra en la figura, el director menciona que la toma de decisiones es importante en cuanto sea correspondiente a un objetivo y beneficie a toda la comunidad educativa o participantes de la circunstancia que se presente. Ello, concuerda con la teoría, por cuanto dice que se trabaja en torno a un objetivo para beneficio de todos los miembros que conforman la organización, logrando así, alcanzar metas estratégicas establecidas en ese sentido (Gordon, 1997).

Para poder llevar a cabo este proceso de toma de decisiones, es necesaria la proyección de un liderazgo eficaz, en este caso de la persona administradora de la educación, con el fin de lograr la mejor influencia sobre la elección de alternativas para la respuesta oportuna que amerita la situación o circunstancia que se presente en la organización. 
Lo anterior, requiere de un proceso o una serie de pasos que lleven a esa elección asertiva a efectos de resolver la problemática manifestada en determinado momento y lugar en la institución educativa. Como lo menciona el personal docente y administrativo del centro educativo en estudio lo importante es analizar el todo y considerar la opción más pertinente según la circunstancia.

El liderazgo que ejerza el profesional en administración de la educación, en este sentido, requiere de dimensiones morales que tomen en cuenta las capacidades y los procedimientos que se emplean para responder a las diversas experiencias que viven las personas, permitiendo valorar la posible intervención que se realice para favorecer su desarrollo y el de la institución en que labora.

Por ello, el liderazgo de la persona profesional en administración de la educación es tan relevante en este proceso de toma de decisiones. En este sentido, el personal docente y administrativo manifiesta lo siguiente:

Profesor: "La toma de decisiones dentro de una institución educativa va a depender del liderazgo que tenga su director a cargo, pues la responsabilidad de lo que suceda dentro del centro educativo es del director, ya sea esto bueno o malo".

Conserje: "La toma de decisiones en un colegio le corresponde al director y a los profesores seguir las indicaciones entorno a lo que decida el jefe".

Como se muestra, ambos consideran que el liderazgo en la toma de decisiones corresponde al director y, el resto de la población educativa, simplemente debe guiarse según las indicaciones que éste de a su equipo de trabajo. De esta forma, en el centro educativo en estudio, se entiende que la responsabilidad de lo que suceda en la institución es del director, pues él es la cabeza de la institución, por lo que todos deben seguir los lineamientos que se den al respecto.

Si bien la opinión no está errada totalmente, considerando el liderazgo de la persona encargada de la administración de la educación, si es necesario enfatizar la oportunidad de crecimiento y mejora que otorga un proceso de toma de decisiones en equipo, a las organizaciones educativas.

En la Figura 2, se consideran las opiniones del director y de su personal docente y administrativo, en relación con el cómo se toman las decisiones en la gestión de la institución en estudio; relacionando las mismas con la teoría que al respecto plantea García (1984). 


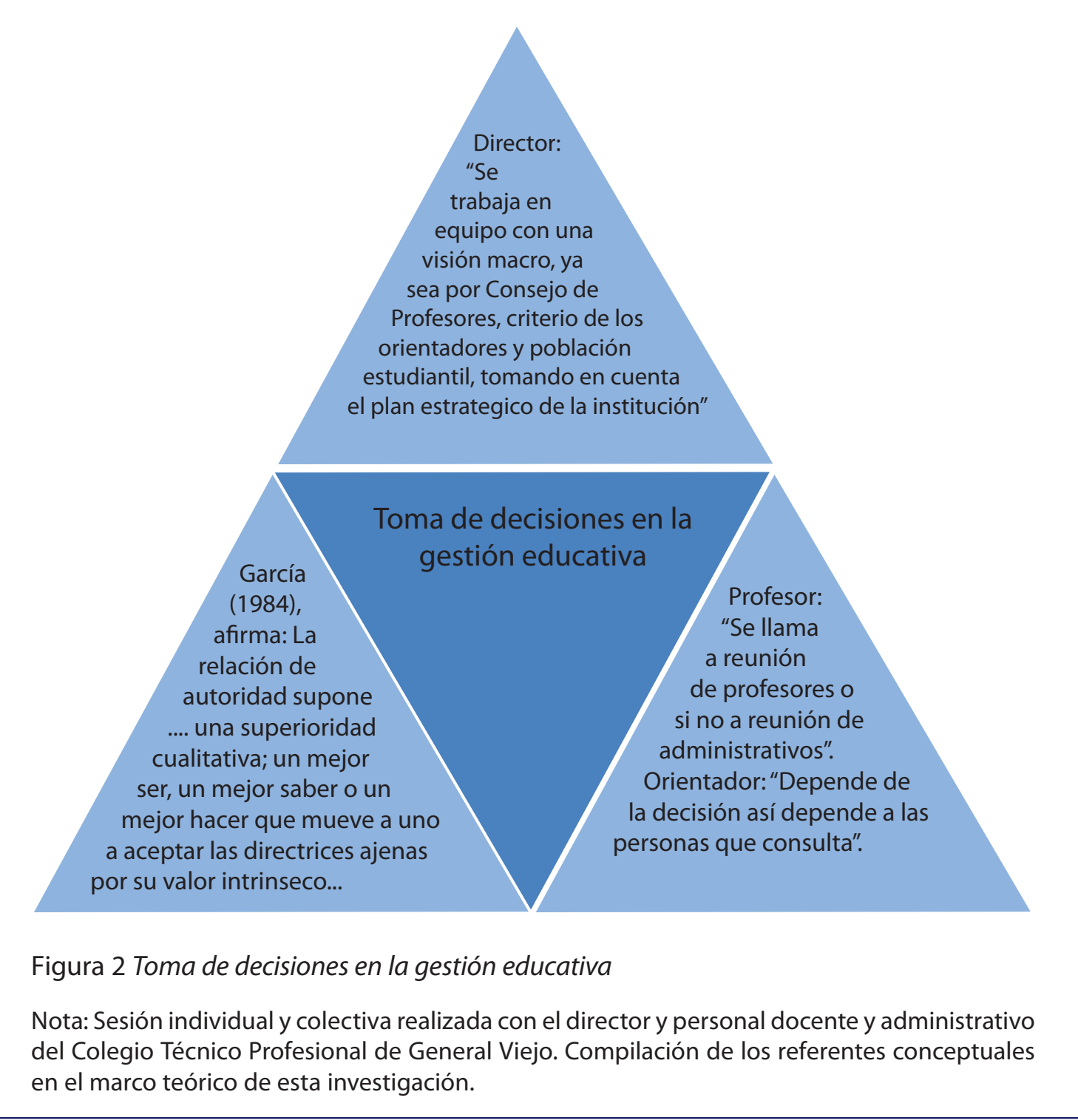

La importancia que tiene la participación de la comunidad educativa en la toma de decisiones de las organizaciones educativas es fundamental para llevar a cabo el proceso de selección de alternativas adecuadas para los problemas indicados. Como refiere García (1984), si bien la autoridad, cualitativamente, permite la definición de metas y objetivos para con su equipo de trabajo, considerando el bienestar personal y colectivo de todos los miembros institucionales, es la gestión del proceso de toma de decisiones en que marca la diferencia, enfatizando la participación de los mismos o rechazando la oportunidad de generar ideas en común, en beneficio de todos. 
En este sentido, el administrador de la educación del Colegio Técnico Profesional de General Viejo, parte del plan estratégico institucional para fomentar el trabajo colectivo con su personal docente y administrativo, además de otros agentes educativos como lo son los estudiantes.

Es decir, en palabras del director, el proceso de toma de decisiones en el Colegio Técnico Profesional de General Viejo, se hace en equipo. El director toma en cuenta el criterio de las personas que laboran y están alrededor de él en su tarea diaria, considerando como punto de partida el plan estratégico de la institución.

Esta acción del administrador de la educación en relación con los procesos de toma de decisiones de la institución que dirige, es relevante en función del trabajo en equipo que se desarrolla con el personal docente y administrativo. Al respecto, se rescata que

La Visión Compartida brinda concentración y energías para el aprendizaje. No se puede imaginar la mayoría de los progresos importantes de cualquier empresa sin la Visión Compartida, de modo que el concepto de visión está de moda en el pensamiento empresarial. (Senge, 1990, p. 9)

Desde esta perspectiva, tomar como base de la toma de decisiones y del trabajo en equipo el plan estratégico, refuerza la idea de determinar, claramente, la dirección que debe tener una organización para conseguir sus objetivos a mediano o largo plazo. Se hace evidente la riqueza en procesos de gestión, de diagnosticar primero, por medio de un análisis situacional, la situación o realidad educativa para permitir organizar, de manera ordenada, los puntos fuertes o débiles, las oportunidades o amenazas del centro educativo y de los procesos de gestión, en relación con el entorno en el cual se desenvuelve para la formulación de estrategias de acción necesarias para alcanzar los objetivos propuestos y, por tanto, la toma de decisiones.

Lo anterior, se complementa también identificando personas estratégicas, de acuerdo con la consulta respectiva a la situación que amerite, logrando establecer las características precisas de la persona indicada para ayudar en el momento adecuado. Un ejemplo de esto, es cuando ante una determinada situación se buscan testigos y personas que han atravesado por circunstancias similares, como lo refiere el personal docente y administrativo:

Bibliotecaria: "A veces toma en cuenta personas que han pasado anteriormente por una caso similar o igual, para hacer una similitud y valorar razones o causas, o debilidades de la institución para así tomar la decisión y pensar en mejoras en su quehacer".

En un proceso de toma de decisiones, se razonan las causas y se identifica el problema, con el fin de hacer mejoras en la gestión diaria de su institución; como se evidencia en este caso, donde se busca no solo solucionar el problema sino también mejorar la administración del centro educativo que el administrador de la educación tiene a su cargo. 
Para ello, la siguiente tabla, muestra la triangulación entre lo que expresa el director y su personal docente y administrativo, en confrontación con la teoría que se suscita al respecto.

Tabla 2

Identificación de problemas en la toma de decisiones
¿El administrador de la educación identifica los
problemas a tratar para
tomar decisiones?

\section{Los administradores en la toma de decisiones}
En una determinada situa- ción ¿Cómo identifica usted el problema a tratar para tomar decisiones?

-Agente de Seguridad: "Él está pendiente de todos los problemas, solo que por motivos externos a veces no se cumplen los propósitos".

-Bibliotecaria: "El está pendiente y tal vez de lo que no se entere los funcionarios se lo hacemos saber".
Los administradores y quienes toman las decisiones también deben evaluarlas de acuerdo con la medida en la que se ciñen los criterios de la ética. Las partes interesadas, los intereses y valores que suelen ser múltiples y discordantes, al igual que las leyes ambiguas, muchas veces conducen a problemas de ética. (Gordon, 1997, p. 214)
-Director: "Primero hay que conocer las situaciones que esta ocasionando el conflicto conociendo las variables, una vez hecho hay que conversar e involucrarse con las partes, así se toma la decisión. Algo muy importante es que los administradores debemos apegarnos al principio legal".

Nota: Sesión individual y colectiva realizada con el director y personal docente y administrativo del Colegio Técnico Profesional de General Viejo. Compilación de los referentes conceptuales en el marco teórico de esta investigación.

Dentro de la toma de decisiones, el director por ser el mayor ente de autoridad institucional, debe intentar, en la medida de lo posible, contemplar los beneficios o perjuicios que pueden presentarse para el personal docente y administrativo, y demás miembros de la comunidad educativa.

Una buena manera de establecer la identificación de problemas controlando los pros y contra que por sí, ya están inmersos en la circunstancia dada, es la que utiliza el director de la institución en estudio, al indicar que lo relevante es conocer la situación que genera el problema y lo que concierne directamente a ella. Así, el administrador de la educación estará consciente de la realidad y podrá tomar las mejores decisiones, de acuerdo con el entorno que se suscita. 
Del mismo modo, es imprescindible que la persona que va a tomar la decisión, en este caso el director, analice quienes están involucrados en ella y de qué forma puede afectarles, también. Es por eso, que la cita de Gordon (1997) es fundamental para sustentar la idea de que las decisiones deben valorarse antes de definir la mejor opción.

Un administrador de la educación debe saber que todas las personas, especialmente docentes y administrativos que trabajan con él, piensan, sienten y creen diferente, lo cual no debe ser un obstáculo para ejercer como profesionales, ni para no desarrollar un proceso en la toma de decisiones. De ahí, la relevancia de señalar la opinión del personal al respecto, quienes consideran que el director siempre está pendiente de ellos y abierto a escuchar lo que tengan que decir.

La toma de decisiones apegada a un código de ética, colabora en no olvidar que los agentes educativos son personas partícipes de la gestión, por cuanto ayuda a que el personal tenga claridad en los valores institucionales y personales por lo que actuarán como puntos focales en situaciones que enfrentan. Es importante que, en ese sentido, se tenga conocimiento de la misión y visión de la organización educativa, para empatar, adecuadamente, la razón de ser como personas con la de la institución donde se labora y así, dirigir los objetivos y metas en una misma dirección como equipo de trabajo. Esta perspectiva, influye directamente en el proceso de toma de decisiones como fiel reflejo que es del comportamiento organizacional.

Todas estas consideraciones, por tanto, son de fundamentales en el proceso de toma de decisiones en la institución, por lo que establecer en un documento lo concerniente a esta tarea y hacerlo del conocimiento del personal y otros agentes educativos permite que el centro educativo tenga un parámetro para la toma de decisiones, sin lugar a interpretaciones personales. Al respecto, el personal menciona:

Conserje: "Él en realidad trata de estar pendiente de todo, pero como todo ser humano no puedo dividirse en veinte para saber de inmediato que es lo que acontece dentro de la institución, por lo que cada uno de nosotros los que trabajamos acá la ayudamos en la que podamos."

Lo anterior, evidencia un equipo de trabajo con claridad de objetivos y orientados por quien lleva la autoridad, el administrador de la educación, quienes con un propósito en común, según la visión, la misión y los valores, optimizan su trabajo y distribuyen funciones para una labor en un contexto íntegro para todos los que componen la comunidad educativa.

De esta forma, es relevante que en la institución educativa se establezcan criterios para la consecución de los objetivos, que sirve como guía para el trabajo del administrador de la 
educación y su equipo de trabajo. La Figura 3, muestra el criterio del director y de su personal docente y administrativo en complemento de la perspectiva teórica existente al respecto.

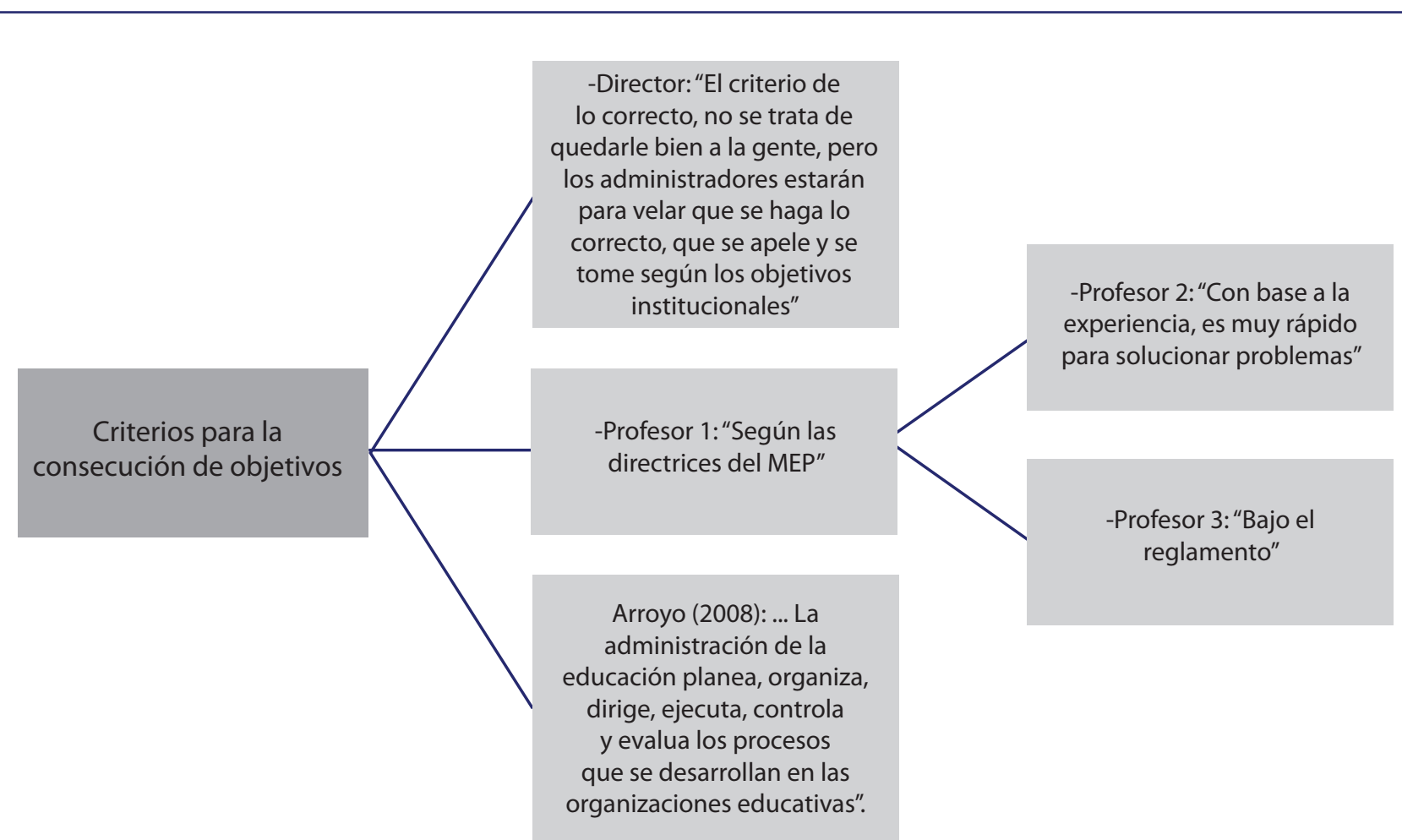

Figura 3

Criterios para la consecución de los objetivos

Nota: Sesión individual y colectiva realizada con el director y personal docente y administrativo del Colegio Técnico Profesional de General Viejo. Compilación de los referentes conceptuales en el marco teórico de esta investigación.

La administración de la educación conlleva una serie de pasos que identifican los procesos de gestión necesarios para la consecución de las metas y objetivos institucionales. Como se presenta en la Figura 3, la administración de la educación determina la planificación, organización, dirección y control de los procesos que se desarrollan en las organizaciones educativas (Arroyo, 2008).

Es así, como dentro de las habilidades que deben desarrollar los administradores de la educación, a partir del criterio y análisis de las investigadoras de este estudio, están: 
- Habilidad de delegar funciones o poder a otro miembro de la comunidad educativa, especialmente a su personal docente y administrativo, para que la gestión de la institución no dependa solo de la autoridad del director, sino de quien corresponda, dependiendo de la circunstancia que se presente, sin evadir la responsabilidad educativa mencionada por Arroyo (2008). Así, el equipo de trabajo de la organización educativa debe verse como un grupo de copartícipes que comparten la responsabilidad por el bienestar de toda la comunidad educativa.

- Habilidad para direccionar la institución, siendo de especial consideración, los procesos de comunicación, en cuanto al análisis y precisión del manejo de información, la evaluación y anticipación de conflictos, entre otros, con el fin operar con rapidez a través de soluciones alternativas, sin que se den mayores complicaciones y con una asertiva toma de decisiones.

Al respecto, "la asertividad es la manifestación adecuada de nuestras opiniones y sentimientos; es decir, sin agredir a los demás pero asumiendo el respeto y dignidad propios" (Vidal, 2000, p. 31). Precisamente, esa es la concepción que el administrador de la educación debe tomar en cuenta a la hora de decidir en función de la comunidad educativa, su personal docente y administrativo y de la misma organización.

- Habilidad para trabajar bajo el criterio de la ética, el compromiso y la responsabilidad institucional. Desde esta perspectiva, las directrices emanadas por el Ministerio de Educación Pública, son un aspecto fundamental con el que se establecen los criterios para la consecución de objetivos que guían el accionar de la organización y de la comunidad educativa como tal. La toma de decisiones se ve, muchas veces, respaldada por las leyes, normativas, reglamentos y resoluciones que amparan el comportamiento del administrador de la educación y del personal docente y administrativo al resolver situaciones concretas por el debido proceso, sin denigrar a ningún agente educativo ni a la misma institución.

Tomando en cuenta las habilidades anteriormente descritas, es necesario enfatizar en las alternativas de solución para la toma de decisiones que considera el administrador de la educación y el personal docente y administrativo del Colegio Técnico Profesional de General Viejo, como insumo fundamental de este proceso de investigación sobre la temática.

\section{Alternativas para la solución de problemas}

Es así, como se presenta la Tabla 3, el cual muestra la opinión de los participantes en cuanto 
a las alternativas en la toma de decisiones que se dan en la institución, las cuales se analizan a la luz de Hastie (2001), en el planteamiento teórico del proceso de toma de decisiones.

\section{Tabla 3}

\section{Alternativas para la toma de decisiones}

\section{Alternativas para la toma de decisiones}
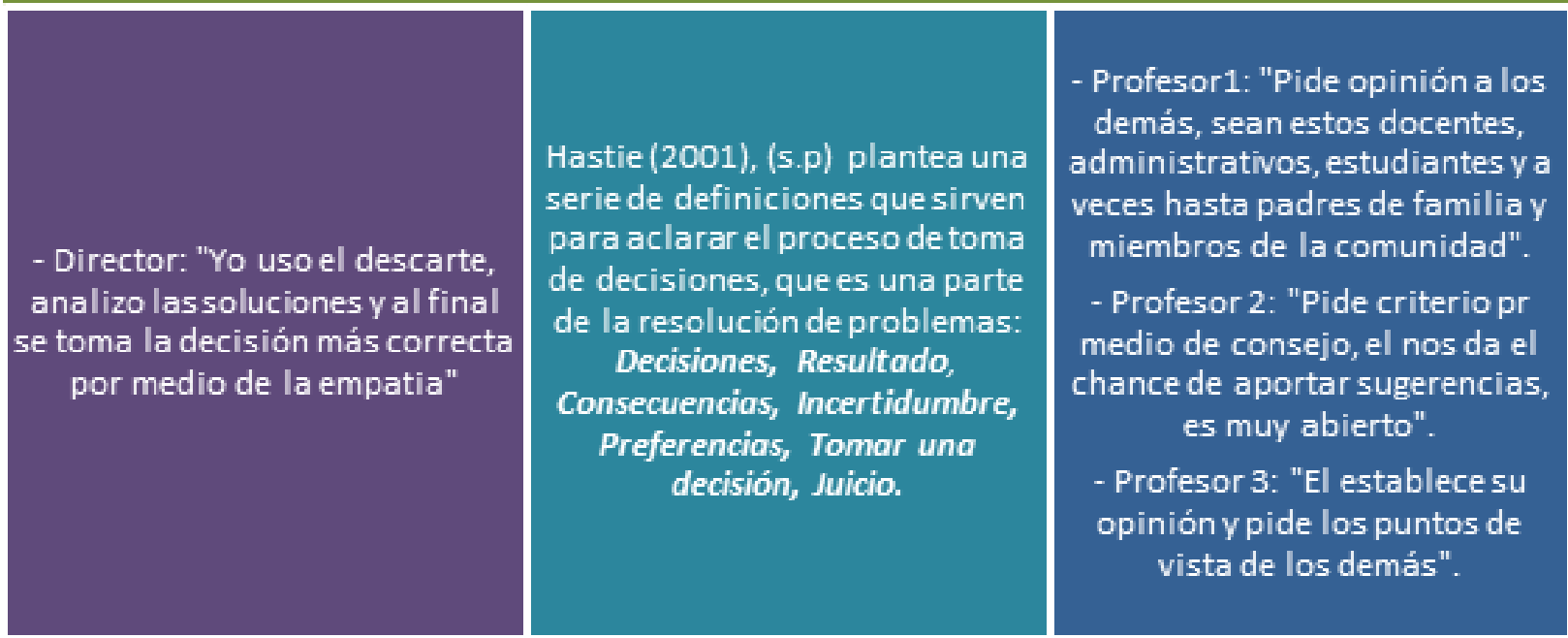

Nota: Sesión individual y colectiva realizada con el director y personal docente y administrativo del Colegio Técnico Profesional de General Viejo. Compilación de los referentes conceptuales en el marco teórico de esta investigación.

Se evidencia en la tabla, que la persona administradora de la educación del Colegio Técnico Profesional de General Viejo, tiene definido en su proceso de toma de decisiones la técnica de descarte, a partir del análisis de las diversas soluciones posibles para la correcta selección de soluciones. El director señala además, considera relevante la empatía, con el fin de asegurar el mejor discernimiento en beneficio de los involucrados en el proceso.

El personal docente y administrativo copartícipe en el proceso, destaca además que el director opta por consultar a diferentes personas antes de tomar decisiones, de tal manera 
que la gama de alternativas de solución y el proceso para decidir, permite escoger al final con asertividad.

Hastie (2001), plantea una serie de definiciones relacionadas con la selección de las alternativas de solución, enfatizando la necesidad de realizar un proceso para la escogencia de la mejor alternativa que colabora en la resolución de conflictos o demás circunstancias que se presentan en la institución. El autor considera que las decisiones, el resultado de las consecuencias que pueden traer las mismas, la incertidumbre que pueda nacer de ellas, las preferencias y las bases fundamentales por las cuales se toman las decisiones, con el fin de que el administrador de la educación pueda crearse un panorama general de lo que implican las alternativas que se lleguen a decidir.

En la administración de esta institución, se evidencia el intento de llevar a cabo una labor integral e integradora, puesto que se toman en cuenta las necesidades básicas de todas las partes involucradas en las diversas circunstancias o situaciones que ameritan la toma de decisiones, sobre todo cuando se trata de un conflicto. De igual manera, la percepción que tienen los docentes acerca de la gestión que realiza el director puede considerarse como buena, dado que valoran el hecho de que se les participe de la toma de decisiones, aunque la aportación que hagan no sea la que se elija para resolver la situación.

La toma de decisiones y el proceso que se realice para llegar a ello, hará que la estructura organizacional de la institución sea la adecuada para poder alcanzar las metas y objetivos propuestos dentro del plan estratégico, influyendo esto en el mejoramiento del ambiente laboral y en la motivación de los miembros del equipo de trabajo.

El personal docente y administrativo respalda la posición descrita para con el administrador de la educación del Colegio Técnico Profesional de General Viejo cuando enfatizan:

Guarda: "Yo he observado que el trata siempre de tener varias opciones para tomar una decisión y que esta sea la correcta al final".

Se retoma entonces, de esta investigación, el hecho de que el director se encarga de desarrollar y examinar las alternativas que tiene para tomar la decisión final, por medio de un proceso que lleva a un listado de todas las alternativas disponibles para la solución de un determinado problema, las cuales se evalúan y analizan con criterios, cuidadosamente seleccionados, tomando en cuenta las ventajas y desventajas de cada alternativa.

Relacionado con lo anterior, se desprenden las categorías de gestión directiva que, desde la perspectiva del administrador de la educación y su personal docente y administrativo, se dan en la institución. Para ello, se presenta, a continuación, la Tabla 4. 
Tabla 4

\section{Categorías de la Gestión Directiva}

\begin{tabular}{cc}
\hline Director & Profesores \\
\hline Jerárquicos & Sistemático \\
& Asertivo \\
Sistemático & Flexible \\
& Programado \\
Asertivo & Jerárquico \\
\hline
\end{tabular}

Nota: Sesión individual y colectiva realizada con el director y personal docente y administrativo del Colegio Técnico Profesional de General Viejo. Compilación de los referentes conceptuales en el marco teórico de esta investigación.

La tabla anterior, refleja las características personales con las que cuenta el director de la institución plasmadas en categorías de la gestión directiva que ejerce en su labor. Dichas características concuerdan tanto entre lo que dicen los docentes y administrativos con lo que menciona el administrador de la institución.

Se constata por este medio, que la labor de dirección se realiza de una manera planificada, ya que se tratan de establecer, con debida anticipación, los objetivos y las acciones que satisfagan las insuficiencias de la comunidad educativa. Es decir, se trabaja de una forma organizada, ordenando los recursos con que se cuenta, dándole la mayor función dentro de la organización al administrador que ejerce la gestión.

En este sentido, la gestión directiva del administrador de la educación, se respalda con el referente de que todo proceso en esa línea enmarca el desarrollo estratégico institucional de manera integral y coherente, en el cual se definen objetivos, acciones y prioridades que comprometen a todos los actores institucionales (Ledo, 2008).

De ahí, la importancia de que el director de una institución educativa cuente con diferentes competencias asistenciales que le permitan una comunicación fluida, multidireccional y asertiva con las diferentes personas con las que labora diariamente; además, debe aplicar el análisis y la síntesis en las situaciones que se presenten, conjugando ambas características con la capacidad valorativa de las causas y consecuencias que traen las mismas. También, deben de considerarse la buena escucha, las habilidades de negociación, de empatía, entre otras. 
Según lo expuesto anteriormente, se puede deducir que el administrador de la educación del Colegio Técnico Profesional de General Viejo, actúa de una forma oportuna al tratar de involucrar a otras personas al momento de tomar decisiones, las cuales les afectan directamente, en el transcurrir del tiempo estratégico institucional.

De acuerdo con ello, se pueden determinar las implicaciones del proceso de toma de decisiones en la estructura organizativa, considerando todos los factores que, en términos de administración y gestión de la educación, refieren al manejo de los recursos humanos, el currículo educativo, entre otros, como se expone en la Figura 4.

La figura deja evidencia de la opinión del director en torno a las implicaciones directas de la gestión del administrador de la educación, sobre la filosofía institucional, a sabiendas de que no todo el personal docente y administrativo está siempre de acuerdo con labor que éste realiza.

El personal resalta que la gestión en el proceso de toma de decisiones, favorecen no solo el cumplimiento del plan institucional sino que también es una pauta relevante en la formación de la labor que todos deben llevar a cabo. Se destaca que es participativo y organizado, pero a su vez, se considera que cuando no se está de acuerdo con algunas decisiones, no se desgastan en contradecir, sino que simplemente se acatan las órdenes, en beneficio de promover un adecuado ambiente de trabajo para todos.

Venegas (2001) manifiesta, al respecto, que como administrador de la educación, el director debe preocuparse de lograr, en su gestión, establecer las políticas, objetivos y propósitos educativos que vayan más allá de su realización, sino que enfaticen también, la formación del personal docente y administrativo y, en general, de toda la comunidad educativa, en la adquisición de conocimientos, actitudes y valores, acordes con la identidad institucional, definida con anticipación para la ejecución de la gestión. 


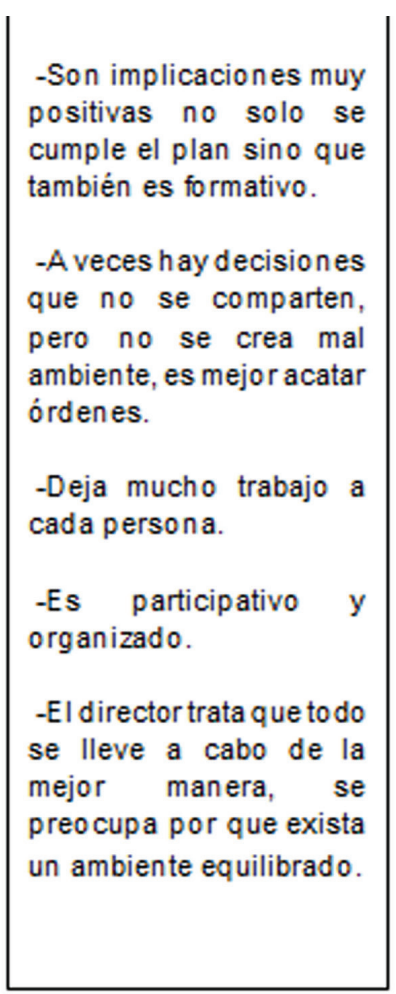

-Son implicaciones muy positivas no solo se cumple el plan sino que también es formativo.

-A veces hay decisiones que no se comparten, pero no se crea mal ambiente, es mejor acatar órdenes.

-Deja mucho trabajo a -Es participativo y organizado.

-El director trata que to do se lleve a cabo de la preocupa por que exista un ambiente equilibrado.

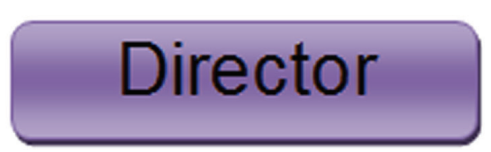

¿Qué implicaciones considera usted que tiene el proceso de toma de decisiones en la institución en aspectos como estructura organizativa, recursos humanos, currículo educativo y manejo de otros recursos?

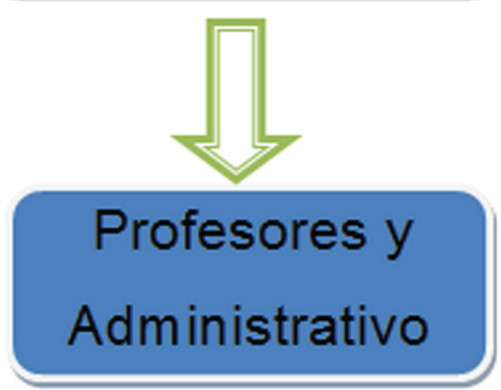

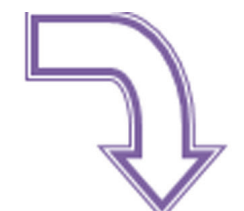

Primero es un a implicación directa, es el director que establece la filosofía institucional; implicaciones positivas y negativas al no estar de acuerdo y se forma un ambiente pesado como se dice, y sabemos que: un $20 \circ 25 \%$ van a estar en contra de la administración.

La gente normalmente critica la toma de decisiones y sin saber porque se to mó la decisión, $y$ eso afecta directamente todos los aspectos.

Venegas (2001) afirma (...) administración de la educación como la ciencia y arte que busca el logro de políticas, objetivosy propósitos educativos mediante el desarrollo de institucionesy programas que fomentan la adquisición de conocimientos, actitudes y valores humanos, sustentados en el currículo institucional, comunitario o regional, nacional y universal-

Figura 4 Implicaciones del proceso de toma de decisiones en la estructura organizativa, recursos humanos, currículo educativo y manejo de otros recursos

Nota: Sesión individual y colectiva realizada con el director y personal docente y administrativo del Colegio Técnico Profesional de General Viejo. Compilación de los referentes conceptuales en el marco teórico de esta investigación. 
De la figura, se desprende, entonces, que por un lado, el dominio de los procesos de gestión y toma de decisiones en relación con los recursos humanos, es una de las capacidades más importantes que debe evidenciar la administración de la educación, siendo que el recurso humano, principalmente, docentes y administrativos, son uno de los factores productivos de la organización.

Tomar en consideración la opinión de su personal, apoyar las decisiones de grupo y la actuación en concordancia con esto, hace que el director no tome criterios fuera de lugar sino que aplique, en su gestión diaria y en las funciones que este realiza constantemente en la institución, el trabajo en equipo que realizan como comunidad educativa.

También, se evidencia que el administrador de la educación del Colegio Técnico Profesional de General Viejo, posee la capacidad para compartir el liderazgo, pues se compromete con su grupo de trabajo y delega en ellos alternativas de decisión, según la situación o el contexto que se esté viviendo en el momento. No obstante, no cede su responsabilidad como administrador en la organización educativa.

La integración del director en las actividades y logros obtenidos dentro del proceso educativo, permite una participación mayor del personal docente y administrativo en la gestión y en la toma de decisiones, estableciendo a su vez, estrategias de refuerzo para las buenas relaciones interpersonales entre todos.

Considerando que la toma de decisiones debe llevarse a cabo como proceso de gestión, se enfatiza que:

La toma de decisiones constituye un proceso cuyo dominio es indispensable para enfrentar y resolver problemas. En este sentido, la capacidad para tomar decisiones es una de las características fundamentales que deben poseer los administradores de la educación. (Lépiz, 2003, p. 64)

Las opiniones del personal docente y administrativo, concuerdan al respecto de indicar que la labor que realiza el director del centro educativo en este sentido, es adecuado para la institución y conforme a las metas y objetivos establecidos en la organización. Lo anterior, se evidencia en el análisis situacional realizado (FODA), tanto con el personal docente como administrativo y con el mismo administrador de la educación.

\section{FODA en relación con el proceso de toma de decisiones}

La información suministrada por los participantes tomando en cuenta cuerpo docente y personal administrativo donde se incluye al director de la institución de este estudio, en relación con los factores internos y externos que dan lugar al análisis situacional de la gestión directiva del 
Colegio Técnico de General Viejo, en cuanto al proceso de toma de decisiones se presenta a continuación, considerando las ocho opciones más relevantes que destacan en las opiniones suministradas.

Al respecto, se presenta la Tabla 5, la cual muestra la síntesis general de los factores internos (fortalezas y debilidades) a la luz de la interpretación de las categorías analizadas para el proceso de toma de decisiones. Es decir, la información que se presenta, correspondiente a las opiniones del personal docente y administrativo están relacionadas con el grado de participación que permite la gestión en la toma de decisiones, la delegación en ese mismo sentido, el liderazgo que desempeña como gestor del proceso, las formas en que se comunican las decisiones, el tiempo que implica el proceso de toma de decisiones y las emociones que genera en el personal docente y administrativo.

\section{Tabla 5}

\section{Factores internos del proceso de toma de decisiones}

\begin{tabular}{|c|c|}
\hline FORTALEZAS & DEBILIDADES \\
\hline $\begin{array}{l}\text { Libertad de expresión del personal docente y } \\
\text { administrativo. }\end{array}$ & $\begin{array}{l}\text { Énfasis en el área técnica, devaluando la formación } \\
\text { integral del estudiante. }\end{array}$ \\
\hline $\begin{array}{l}\text { Disponibilidad del personal administrativo y docente } \\
\text { para la toma de decisiones. }\end{array}$ & $\begin{array}{l}\text { La administración no ofrece la confidencialidad en los } \\
\text { procesos. }\end{array}$ \\
\hline Se fomenta el trabajo en equipo delegando funciones. & Falta de espacios recreativos. \\
\hline Servicios que brinda la institución para facilitar el & Se apega mucho en el reglamento. \\
\hline $\begin{array}{l}\text { proceso de enseñanza y aprendizaje. } \\
\text { Administración adecuada de los recursos. }\end{array}$ & Disconformidades del personal docente $y$ \\
\hline $\begin{array}{l}\text { Administración adecuada de los recursos. } \\
\text { Apoyo de la administración a los diversos problemas }\end{array}$ & administrativo en el proceso de toma de decisiones. \\
\hline $\begin{array}{l}\text { Apoyo de la administración a los diversos problemas } \\
\text { del personal docente y administrativo. }\end{array}$ & $\begin{array}{l}\text { Desconocimiento del personal en los procesos } \\
\text { legales. }\end{array}$ \\
\hline Facilidad de que el estudiante elija especialidad & Imposición de la administración. \\
\hline técnica. & Poca motivación al personal docente y al cuerpo \\
\hline Comunicación asertiva. & estudiantil. \\
\hline
\end{tabular}

Nota: FODA realizado por el personal docente y administrativo del Colegio Técnico Profesional de General Viejo.

La tabla refleja que en los aspectos internos, el personal docente y administrativo, considera que en la gestión del proceso de toma de decisiones se goza de libertad de expresión, disponibilidad por parte de ellos, trabajan en equipo, tienen apoyo de la dirección ante los problemas que se les presentan, entre otros. Como debilidades, se apuntan las siguientes: administración no confidencial de los procesos, apego al reglamento, disconformidades del personal en cuanto al proceso de toma de decisiones, imposición de la administración, otros. 
Al respecto, las debilidades se especifican en los siguientes rubros:

- El programa de la institución se enfoca en la formación técnica y deja de lado la formación integral de los estudiantes, dado que se considera como prioridad la inducción laboral más que la formación en valores, lo cual indica que no se la tomado el aparecer a la demás comunidad educativa.

- La administración no ofrece la confidencialidad en los procesos en la toma de decisiones, argumentando que los problemas de la institución son problemas de todos y no de algunos cuantos. La confidencialidad está bien definida por de manera que evidencia confianza y seguridad a todos los involucrados en el proceso de formación.

- Se encuentran los espacios para la recreación, pero no la infraestructura o materiales que brinden el esparcimiento como tal, esto como un indicador de cómo se distribuyen los ingresos de la institución y las prioridades de la misma.

- Disconformidad del personal con el proceso de toma de decisiones, pues se toman en cuenta los criterios pero al final el administrador de la educación es quien decide, sin preguntar a su personal o personas involucradas, si están o no de acuerdo. Se resalta que lo hace de manera impositiva y muy apegada al reglamento, dejando a veces de lado la flexibilidad, por lo que se dedican solamente al seguimiento de órdenes.

Esta última debilidad, deja entrever, que si bien existe un proceso de gestión donde se consideran los pareceres de la comunidad educativa, como se analizó en la primera parte de este apartado, al final no se llega a un proceso totalmente participativo, pues las decisiones finales las toma el administrador de la educación y se da el acatamiento de la misma.

Entre la información del FODA y de las sesiones colectivas, se evidencia una diferencia en cuanto se menciona la no confidencialidad de los procesos y las disconformidades del personal en relación, además, de la imposición de la dirección. Por lo que es relevante considerar esta información, para el análisis que se presenta más adelante.

Por su parte, los factores externos (oportunidades y amenazas), se relacionan con las categorías que trabajan las condiciones en que se toman las decisiones, la comunidad educativa que influye en el proceso, en contexto o entorno y las instancias superiores que tienen que ver, directamente, con el rubro de la investigación. La Tabla 6 presenta, como la anterior, la síntesis general de las opiniones suministradas por el personal docente y administrativo del Colegio Técnico Profesional de General Viejo y el director del mismo. 
Tabla 6

Factores externos del proceso de toma de decisiones

\section{OPORTUNIDADES}

Servicios públicos que ofrece la comunidad a la institución.

Docentes de la misma zona.

Apoyarse según lo estipule el reglamento.

Acompañamiento de la comunidad educativa en la toma de decisiones.

Personal altamente capacitado.

Apoyo del Ministerio de Educación en los debidos procesos.

Apoyo de las universidades a la institución en el proceso de inducción del estudiantado.

Oportunidades que brinda la administración para procesos formativos laborales.

\section{AMENAZAS}

Comunidad desinteresada en el proceso de enseñanza aprendizaje.

Problema de consumo y venta de drogas.

Recorte de presupuesto.

Sitios de riesgo (bares y ríos) cerca de la institución.

Influencia de otras poblaciones problemáticas.

Déficit en los nombramientos.

Falta de capacitación integral al personal docente y administrativo.

Mucha exigencia de parte del MEP, dando poco por parte de la misma institución.

Nota: FODA realizado por el personal docente y administrativo del Colegio Técnico Profesional de General Viejo.

En relación con la tabla anterior, se destacan algunas oportunidades como la facilidad de servicios públicos que la comunidad tiene a su alcance, entre ellos reconocen la presencia de los Equipos Básicos de Atención Integral en Salud (EBAIS), Comedor Infantil, Guardia Rural, entre otros, que en situaciones difíciles están a disposición inmediata de la organización educativa.

Además, el hecho de que los docentes sean de la misma zona es una ventaja, ya que les permite un acercamiento que promuevelaconfianzayestabilidad delainstituciónal noalternar, muyconstantemente, los docentes; adicional a eso, la gran mayoría de éstos tiene un grado de Licenciatura como título mínimo.

Se consideran también, como oportunidad, los servicios que brinda la institución para facilitar el proceso de enseñanza y aprendizaje, desde fotocopiadoras, comedor estudiantil, soda, suficientes baterías sanitarias, otros.

En cuanto a las situaciones que causan daños a la institución, a terceros o a si mismos, se enfatiza que se rigen, según lo estipula el reglamento, bajo un debido proceso. El objetivo de este proceso es procurar que las personas o los afectados tengan interés en defender, adecuadamente, sus derechos a lo interno del mismo.

En relación con los espacios recreativos, los cuales son de suma importancia, tanto para los estudiantes como para el mismo personal docente y administrativo en tiempo de ocio, se indica 
que permiten el desarrollo psicológico, cognitivo y físico, por lo que es uno de los beneficios que pueden recibir, lo que contribuye a la construcción de identidad y a la promoción de acciones que disminuyen problemas sociales como drogas, delincuencia, incomunicación, entre otros.

De esta manera, los espacios recreativos se convierten en áreas de esparcimiento y creación de pensamientos positivos, lo que hace que. Al menos los estudiantes, tengan menos tiempo para realizar acciones o involucrarse en situaciones de riesgo para la institución, lo que prevé que se den situaciones conflictivas

Una oportunidad presente en la Tabla 5, en conjunto con una de las fortalezas mencionadas en la Tabla 6, es el hecho de que los estudiantes puedan elegir libremente la especialidad que desean para su formación, por lo que salen del centro educativo con una formación laboral, pues salen con un técnico medio. Lo anterior, abre la posibilidad de que encuentren empleo cuando se gradúen. Un listado de las especialidades que brinda esta institución es el siguiente:

- Industria de la Madera,

- Artesanías Artístico - Utilitarias,

- Construcción Civil,

- Metal Mecánica,

- Decoración de Interiores,

- Diseño y construcción de muebles de madera,

- Industria textil,

- Informática en Programación,

- Informática en Redes,

- Informática en Soporte,

- Informática en Desarrollo de Software,

- Secretariado Bilingüe,

- Secretariado Ejecutivo

- Dibujo Arquitectónico.

En relación con las amenazas manifestadas por el personal docente y administrativo, se puede considerar que entre los problemas o situaciones más intimidan son:

- Que la comunidad, el día de mañana, se sienta desinteresada del proceso de enseñanza aprendizaje, dejando de lado a la institución y las situaciones problemáticas o de atención que emergen de ella. 
- El consumo y la venta de drogas presente en las comunidades, es un mal difícil de controlar y detectar a corto plazo; sumado, lo anterior, a los sitios de riesgo que se encuentran en los alrededores como lo son bares y ríos de fácil acceso pero de poca vigilancia, son amenazas latentes que deben considerarse en la gestión del proceso de toma de decisiones, liderada por el administrador de la educación. Además, la existencia de comunidades cercanas conflictivas y la presencia de un personal capacitado en su área de enseñanza, mas no en aspectos básicos sociales, emocionales o disciplinarios, dificultad la labor en variadas ocasiones.

- El recorte de presupuesto para las instituciones, impide el crecimiento en infraestructura, materiales didácticos, entre otros recursos necesarios para el desarrollo de la labor docente y administrativa; además, por la misma causa, se produce un recorte de nombramientos de personal en fechas diferentes al comienzo de clases, atrasando así, el plan de estudios y por ende, los procesos de toma de decisiones.

A partir de la exposición del análisis del FODA, se establece una interrelación cruzada entre factores internos y externos. De dicho cruce de información, surgen objetivos estratégicos que brindan opciones para la gestión del proceso de toma de decisiones en el centro educativo en estudio. En ese sentido, la Tabla 7 presenta los objetivos estratégicos que dan lugar a posibles acciones de toma de decisión por parte del administrador de la educación y su equipo de trabajo.

\section{Tabla 7}

\section{Objetivos estratégicos emergentes del FODA}

\section{OBJETIVOS ESTRATÉGICOS}

1. Fomentar la participación activa del personal docente y administrativo en el proceso de toma de decisiones.

2. Reforzar el interés por parte de los miembros de la comunidad en el proceso de enseñanza aprendizaje.

3. Implementar un nuevo modelo de toma de decisiones en la gestión administrativa.

4. Incentivar a la administración para que involucre a la comunidad educativa en el proceso de toma de decisiones.

Nota: FODA realizado por el personal docente y administrativo del Colegio Técnico Profesional de General Viejo.

\section{A modo de conclusión}

La investigación concluye que existe un proceso de gestión no del todo participativo, en el que la opinión de la comunidad educativa para el proceso de toma de decisiones, se consideran parcialmente. A 
su vez, la disposición de los docentes y administrativos para llevar a cabo el proceso de toma de decisiones es abierto, y están dispuestos a escuchar opciones para que el proceso se de manera participativa.

De ahí, que el cuerpo docente sienta descontento cuando no se les toma en cuenta en la totalidad del proceso.

Entre algunas de las estrategias de gestión para el proceso de toma de decisiones se consideran: la intuición, lo que deja de lado la sistematización, la planeación y planificación de futuras situaciones; la técnica del descarte, comenzando por el análisis de varias soluciones posibles para la correcta selección de la misma. También señala el director como un aspecto importante, la empatía esto para poder asegurar el mejor acierto en beneficio de los involucrados en el proceso.

En ese sentido, para el mejoramiento del proceso de toma de decisiones en el CTP General Viejo, se propone un modelo estratégico de gestión en el que se involucre la participación de la comunidad educativa, con el fin de que se pase de una dinámica actual, centralizada en su mayoría en la toma de decisiones por parte del director, como se muestra en la Figura 6, a un proceso consensuado, desde el inicio, tal como lo presenta la Figura 7.

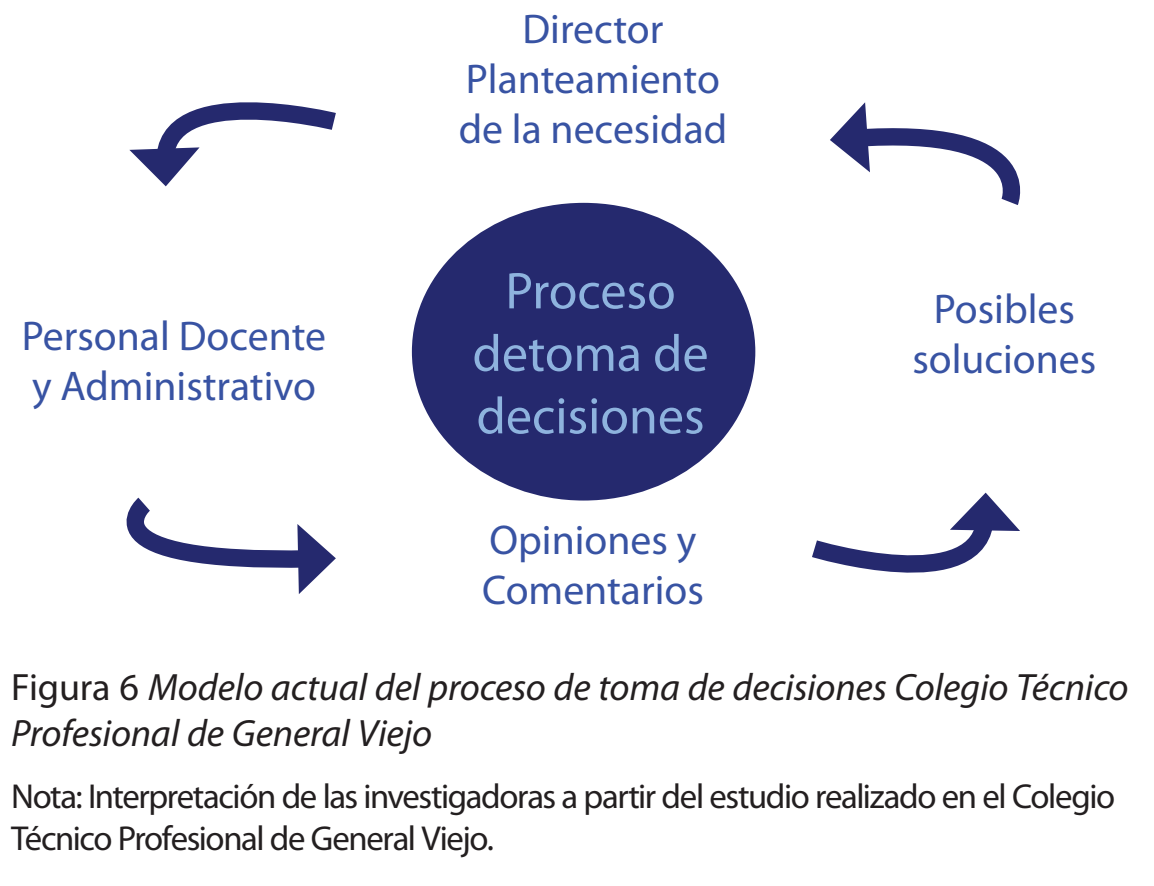

La figura anterior, refleja el ciclo del proceso de toma de decisiones que, actualmente, impera en el centro educativo mencionado. Explica cómo el proceso inicia y concluye con 
el director, pasando por etapas donde el mismo se relaciona con el personal docente y administrativo para solicitar los comentarios relacionados con la situación que se está dando; con las opiniones suministradas por el personal, se llega a posibles soluciones, pero como indica la flecha, al final la elección queda en manos del administrador de la educación, como jerarca de la organización.

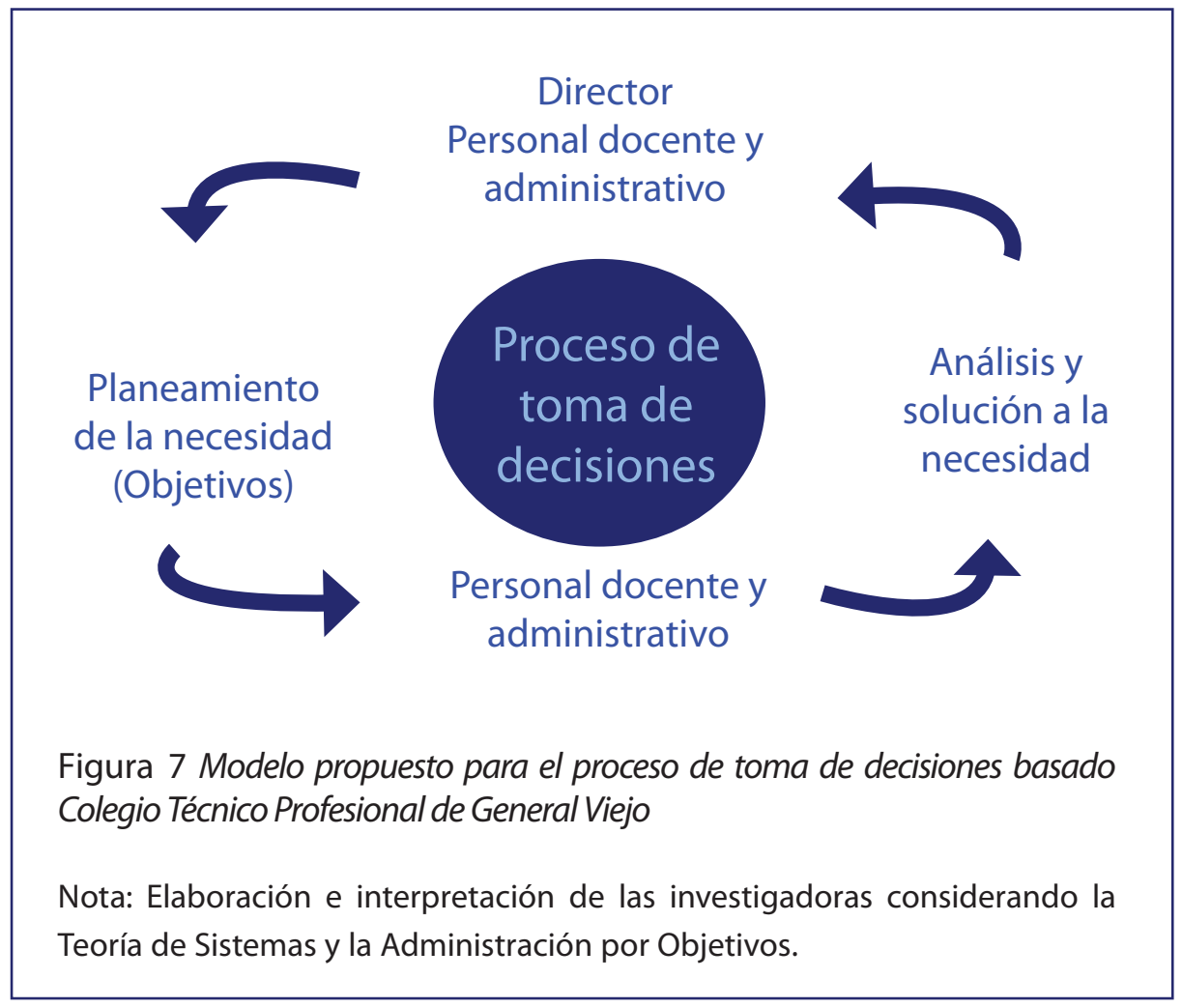

De acuerdo con la figura anterior, el nuevo comportamiento de la gestión del proceso de toma de decisiones, renueva el ciclo por medio del cual se analizan y seleccionan las alternativas de solución, que dan lugar a las decisiones. El aporte del mismo, es la mayor participación del personal docente y administrativo en la gestión del proceso, como lo explica la Teoría General de los Sistemas, la cual afirma que las propiedades de los sistemas no pueden describirse, significativamente, en términos de sus elementos separados. De ahí, la importancia de considerar la participación del administrador de la educación y de su personal docente y administrativo, en el mismo estrato del proceso, del cual parte todo el análisis y reflexión de la situación (objetivo) para la toma de decisiones al respecto.

La idea de este nuevo modelo, radica en crear una cultura organizacional donde cada individuo sea parte del proceso y todos se enfoquen en objetivos comunes para la toma de decisiones. 


\section{Referencias}

Arroyo, J. A. (2009). Gestión directiva del currículum. San José, Costa Rica: EUCR.

Caldeiro, G.P. (2005). Teoría de la comunicación. Recuperado en: comunicacion.idoneos.com/ index.php/Teoría_de_la_comunicación

Castillero, A.; Díaz, J.; Morales, F. y Pino, I. (2009). Gestión y supervisión en el centro de educación básica. Coordinación Educativa y Cultural Centroamericana. Recuperado en: http://www. ceducar.info/ceducar/recursos/biblioteca\%20online/Volumen\%2036/HTML/files/assets/ basic-html/page132.html

Chiavenato, I. (2006). Introducción a la Teoría General de la Administración. México: McGraw-Hill.

Dilts, R. (1998). Liderazgo creativo. Barcelona: URANO, S.A.

Drucker, P. (1954). La sociedad pos capitalista. Bogotá: Editorial Norma.

Durkheim, E. (1991). Educación y sociología. México: Editorial Colofón.

Salas M., F.E. (2003). La administración educativa y su fundamentación epistemológica. Revista Educación, 27(1), pp. 9-16. Recuperado en: http://www.redalyc.org/articulo.oa?id=44027102

Garbanzo V., G.M. y Orozco D., V.H. (2007). Desafíos del sistema educativo costarricense: un nuevo paradigma de la administración de la educación. Revista Educación, 31(2), pp. 95-110, ISSN: 0379-7082. Recuperado en: http://www.latindex.ucr.ac.cr/educacion-31-2/06-GARBANZO. pdf

Garcia C., J. (1984). Teoría de la educación. En: A. Escolano (ed.), Diccionario de Ciencias de la Educación. Madrid: Anaya.

Gordon, J. (1997) Comportamiento organizacional. México: Prentice Hall Hispanoamericana S.A.

Hall, R. (1983). Organización, estructura y procesos. Madrid, España: Prentice Hall Internacional.

Hastie, R. (2001). Patología de la toma de decisiones. Annual Review of Psychology. Recuperado en: http://www.psicoterapeutas.com/pacientes/patologiatomadecisiones.htm

Hernández, R.; Fernández, C. y Baptista, P. (2010). Metodología de la investigación. México: Mc GrawHill Interamericana Editores.

Herrera C., I. (s.f.). Proceso de toma de decisiones. Recuperado en: http://www.monografias.com/ trabajos36/toma-decisiones/toma decisiones2.shtml. 
Lakoff, G. y Mark, J. (1986). Diccionario de la Lengua Española. Real Academia Española. Recuperado en: http://rae.es/recursos/diccionarios/drae

Ledo V., M.; Durán G., F. y Pujal V., N. (2008). Gestión educativa. Recuperado en: http://webcache. googleusercontent.com/search?q=cache:OqHSAGSTgVMJ:bvs.sld.cu/revistas/ems/ vol22 2 08/ems12208.htm+Ledo+definici\%C3\%B3n+de+objetivos,+acciones+y+prioridad

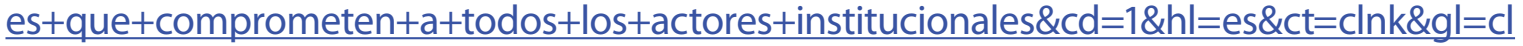

Lépiz, H. (1986). Administración y planificación como procesos. San José, Costa Rica: EUNED.

Montenegro, G.; Camiña, S.; Muños, C. y Mazza, P. (2007). Liderazgo. Curso de gerenciamiento de organizaciones sanitarias. Recuperado en: www.admisal.com.ar/descargas/LIDERAZGO.doc

Ortegón, E.; Pacheco, J. F. y Roura, H. (2005). Serie manuales, metodología del marco lógico para la planificación, el seguimiento y la evaluación de proyectos y programas. CEPALILPES. Recuperado en: http://www.eclac.cl/cgi-bin/getProd.asp?xml=/ilpes/agrupadores_ xml/aes114.xml\&xsl=/agrupadores_xml/agrupa_listado.xsl\&base=/ilpes/tpl/top-bottom.xsl

Pastori, H. (2010). Ideas para el desarrollo. Metodología para el desarrollo de trabajos. Recuperado en: http://decon.edu.uy/100jovenes/materiales/ideas\%20para\%20el\%20desarrollo2.pdf

Robbins, S.P. (1998). Introducción al comportamiento organizacional. México: Prentice Hall.

Heifetz, R. y Linsky, M. (2003). Manual de supervivencia para líderes. Harvard Deusto Business Review, ISSN 0210-900X, 110. Recuperado en: http://solidonorte.com/files/escuela_popular/ Heifetz_Linsky\%20Manual\%20de\%20supervivencia\%20para\%20lideres.pdf

Rycroft, Ch. (1976). Diccionario de psicoanálisis. Buenos Aires: Paidós.

Senge, P. (1990). La Quinta Disciplina. El arte y la práctica de las organizaciones que aprenden. USA: Editorial Currency.

Venegas, P. (2001). Retos y perspectivas de la administración educativa en un nuevo milenio. San José, Costa Rica: EUNED.

Vidal, M. (2000) Autoestima y motivación. Bogotá: Cooperativa Editorial Magisterio. 